\title{
Carbon fiber reinforced shape memory epoxy composites with superior mechanical performances
}

\author{
Yayun Liu ${ }^{\mathrm{a}, \mathrm{b}, 1}$, Yufeng Guo ${ }^{\mathrm{a}, 1}$, Jun Zhao ${ }^{\mathrm{a}, *}$, Xiaodong Chen ${ }^{\mathrm{c}}$, Hui Zhang ${ }^{\mathrm{a}}$, Guoqing $\mathrm{Hu}^{\mathrm{d}}$, \\ Xiang $\mathrm{Yu}^{\mathrm{e}, * *}$, Zhong Zhang ${ }^{\mathrm{a}, * * *}$ \\ ${ }^{a}$ CAS Key Laboratory of Nanosystem and Hierarchical Fabrication, CAS Center for Excellence in Nanoscience, National Center for Nanoscience and Technology, Beijing \\ 100190, China \\ ${ }^{\mathrm{b}}$ School of Engineering and Technology, China University of Geosciences (Beijing), Beijing 100083, China \\ ${ }^{\mathrm{c}}$ School of Aerospace Engineering, Beijing Institute of Technology, Beijing 100081, China \\ ${ }^{\mathrm{d}}$ State Key Laboratory of Nonlinear Mechanics, Institute of Mechanics, Chinese Academy of Sciences, Beijing 100190, China \\ ${ }^{\mathrm{e}}$ School of Materials Science and Engineering, China University of Geosciences (Beijing), Beijing 100083, China
}

\section{A R T I C L E I N F O}

\section{Keywords:}

Shape memory epoxy

Carbon fiber

Composites

High stiffness

\begin{abstract}
A B S T R A C T
For the shape memory polymers' (SMPs) applications in demanding, high performance scenarios are usually limited by their poor mechanical performances during shape transformation. In this work, shape memory epoxy composites (SMEPCs) with superior mechanical properties are fabricated by adding various short and continuous carbon fibers (CFs) into neat shape memory epoxies (SMEPs) matrix. The resultant SMEPC's storage modulus ( $E$ ) at room temperature is as high as $37 \mathrm{GPa}$, and the maximum recovery force exceeds $4.4 \mathrm{GPa}$, with good shape memory capabilities. These properties are at least an order of magnitude higher than those in existing typical SMP systems. The excellent mechanical properties of the fibers and their ability to retard crack propagation in the matrix are believed to play an important role in achieving high moduli below and above the shape-memory triggering temperature. The potential applications of such SMEPCs are demonstrated with wind blades. Experimental results and numerical models regarding air flow velocity variation as initiated by shape change in the blades indicate that our SMEPCs can sustain continuous stable mechanical state and provide variable wind speeds. These CF reinforced SMEPCs can be employed as smart structural materials to automatically switch shapes in response to the change in environment, such as those seen in aero foils and energy harvesters.
\end{abstract}

\section{Introduction}

Shape memory polymers (SMPs) are a class of stimuli-responsive smart materials that can be deformed into temporary shapes for extended periods before recovering to their original equilibrium shapes with a triggering stimulus [1-3]. Compared with shape memory alloys (SMAs) and shape memory ceramics (SMCs), SMPs have several unique properties, including: (i) a large variety in potential activation mechanisms, such as heat, magnetism, electric fields, light, moisture, $\mathrm{pH}$, etc. [4,5]; (ii) massive (up to 700-1000\%) recoverable deformation and simplified processing requirements [6,7]; (iii) easy and programmable control over key mechanical properties, including switch temperature $\left(T_{\text {sw }}\right)$, recovery force, multiple shape memory effects (SMEs), biodegradability, and functional grading potential $[8,9]$.
The latest developments in structural design, chemical synthesis, and nanotechnology have enabled SMPs to realize complex transformation and body temperature triggering, but not structural applications where high modulus and fast recovery are required [10]. Generally, temporary shape deformation and shape recovery occur when the SMPs are heated into a highly elastic state, which is accompanied by a rapid decline in stiffness. Specifically, there is a large change in elastic modulus $(E)$ or storage modulus $\left(E^{\prime}\right)$ between the room temperature $(R T)$ and transformation temperature states, resulting in a dramatic loss of basic mechanical performance [11]. Currently, the $E$ ' over the $T_{\mathrm{sw}}$ of SMPs is $1-30 \mathrm{MPa}$ that means the samples are too weak in their heated state to serve as useful structural materials. Actually, SMPs with adequate mechanical stiffness during the transition process can have a lot of technical significance [3].

\footnotetext{
*** Corresponding author.

* Corresponding author.

** Corresponding author.

E-mail addresses: zhaoj@nanoctr.cn (J. Zhao), yuxiang@cugb.edu.cn (X. Yu), zhong.zhang@nanoctr.cn (Z. Zhang).

${ }^{1}$ Contributing equally to this work.
} 


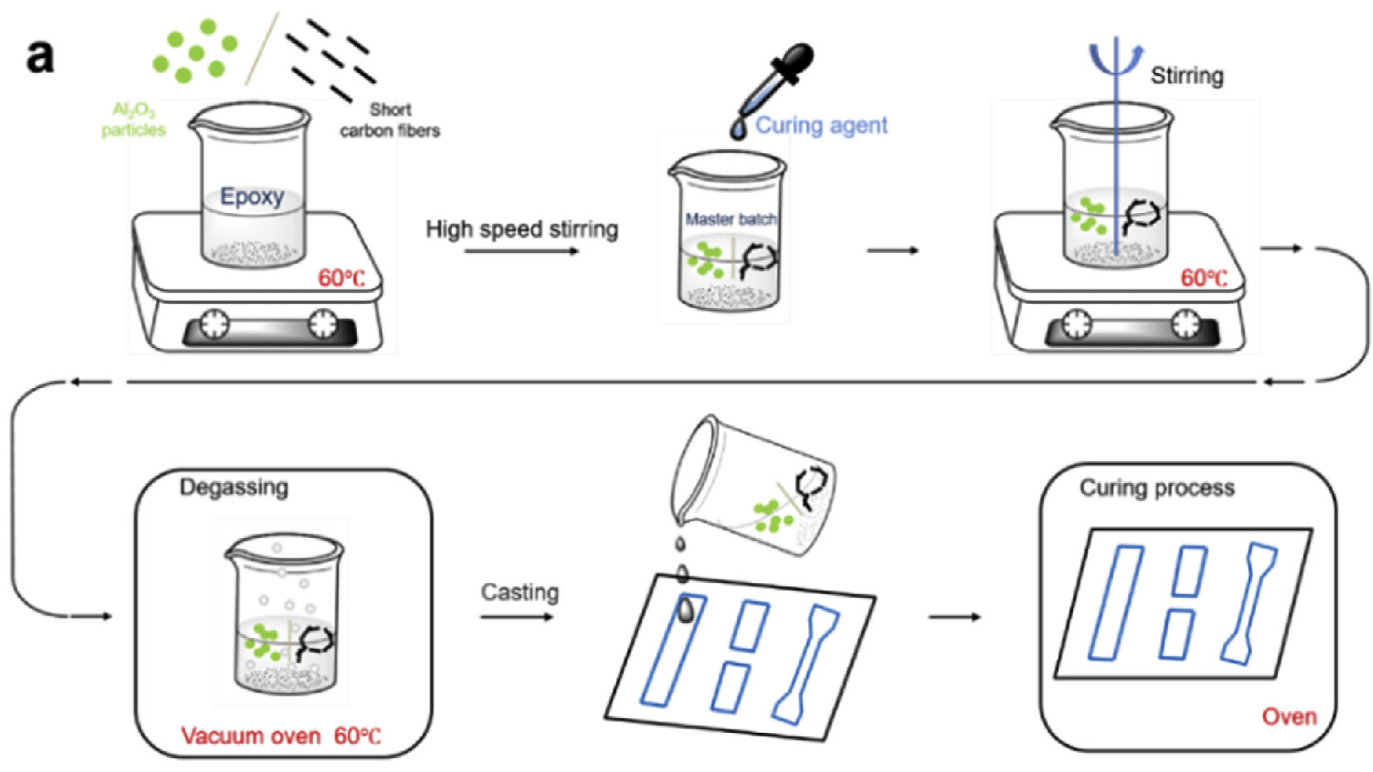

Preparation process of non-continuous system

b

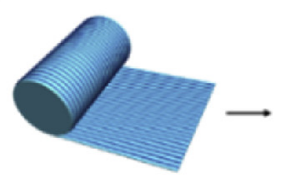

Pre-preg carbon fibers

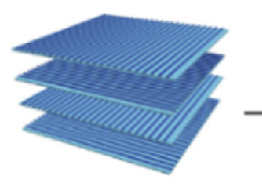

Cross pile up

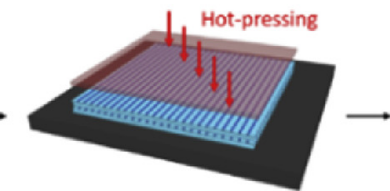

Layer by layer hot pressing

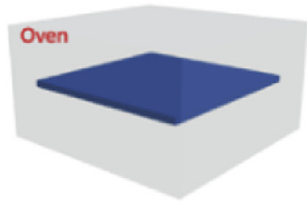

Curing Process
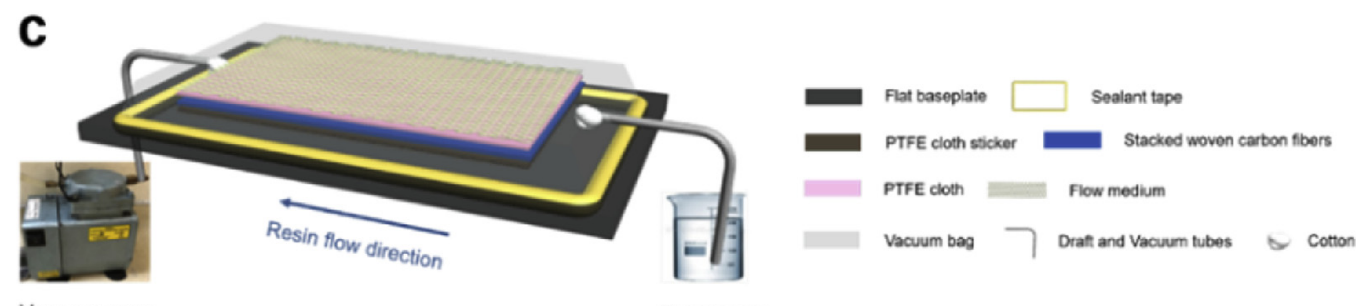

Vacuum pump

Epoxy resin

\section{Preparation process of continuous system}

Fig. 1. Schematic illustration of SMEPCs preparation process with non-continuous (a) and continuous filler systems (b and c).

Both matrix materials selection and composites preparation are well-regarded options to reinforce the mechanical properties of SMPs $[11,12]$. Thermoset shape memory epoxies (SMEPs) are a good choice of matrix materials given their high $T_{\mathrm{sw}}$, high shape fixation and recovery ratios, rapid shape response, superior environmental durability, excellent dimensional stability, and easy processing [3,13]. Concerning their SME, cross-linking reaction occurs during the curing process of epoxy resin and the resulted cross-linking points guarantee the permanent shape; the glass transition temperature $\left(T_{\mathrm{g}}\right)$ works as a switch of shape change; the segmental flexibility and long enough chains provide large enough deformation (forming temporary shape) above the $T_{\mathrm{sw}}$. The preparation of SMEP composites (SMEPCs) by adding fillers into the matrix is often beneficial to the improvement of SME, mechanical properties, and functionality. Among various fillers, carbon fibers (CFs) stand out as a lightweight carbon material that could add targeted properties to the composites. Both short CFs (SCFs) and continuous CFs are combined with polymers to form CF-reinforced composites that demonstrate varying mechanical properties, electrical conductivities, and thermal-responsive performances. Additionally, epoxy matrix can be a good binder to produce composites with superior strength and stiffness due to the good filler dispersion and strong interfacial bonding between them [14-16].

There are already some literatures reporting the high performance SMEPs, CF-reinforced epoxy composites, and their applications. For example, one work from Feng's group reported the SMEPCs with NiTi wires, showing much higher stiffness at elevated temperature than the 
pure SMEPs. Adding only 1 vol\% NiTi wires could increase the maximum recovery force from ca. $1.36 \mathrm{MPa}$ to ca. $4.04 \mathrm{MPa}$ [13]. Our previous study showed a series of SMEP/multi-wall carbon nanotubes (MWCNTs) nanocomposites with good comprehensive performance. The addition of $0.75 \mathrm{wt} \%$ MWCNTs could significantly increase the $E^{\prime}$ at $R T$ up to ca. 3.3 GPa and the recovery stress up to ca. $30 \mathrm{MPa}$ at $T_{\mathrm{sw}}$ [3]. Moreover, a deployable truss structure made of the fiber reinforce epoxy-based SMP composite was fabricated by Leng et al. [17]. The materials' $T_{\mathrm{g}}$ was around $100^{\circ} \mathrm{C}$, and their $E^{\prime}$ reached $14.5 \mathrm{GPa}$ at $R T$ and about $1 \mathrm{GPa}$ at $T_{\mathrm{sw}}$. Although the study on SMEPCs has progressed steadily, the mechanical properties, especially the stiffness during shape changing, still need further improvement.

In this work, a series of SMEPCs with ultra-high stiffness and good SME using non-continuous and continuous fillers are systematically investigated. The non-continuous fillers include SCFs with various length-diameter ratios $\left(r_{\mathrm{L} / \mathrm{D}}\right)$ and $\mathrm{Al}_{2} \mathrm{O}_{3}$ particles. The continuous fillers comprise woven fabrics and pre-preg CFs. The resultant excellent mechanical properties can ensure these SMEPCs to be used in some industrial scenarios that need high stiffness of the materials, such as wind blades. Therefore, the potential applications are demonstrated as deformable wind blades to simulate and test the wind speeds when the blades' compositions and shapes are changed. These CF-reinforced SMEPCs can also be employed as smart structural materials to adapt to the environmental changes, such as those seen in aero foils and energy harvesters [18].

\section{Material and methods}

\subsection{Materials}

The epoxy resin E51, curing agent methylhexahydrophthalic anhydride (MHHPA) and accelerator, $N, N$-benzyl dimethyl amine (BDMA) as the matrix materials were based on our previous work [3]. $\mathrm{Al}_{2} \mathrm{O}_{3}$ particles with the diameter of $2-15 \mu \mathrm{m}$ were provided by Evonik Degussa Industries (Germany). T300 SCFs with the various $r_{\mathrm{L} / \mathrm{D}}(6,6-10,33$, and 400), T300 pre-preg CFs and CP3K-240 plain woven fabrics were purchased from Jilin Jiyan High-Tech Fibers Co. Ltd. China, and Shanghai Liso Composite Material Co. Ltd. China. All chemicals were used as received.

\subsection{Sample preparation}

The preparation of non-continuous filler-based SMEPCs is indicated in Fig. 1a. The preparation steps except the type of fillers were the same as the previous work [3]. SCF with various $r_{\mathrm{L} / \mathrm{D}}$ from 6, 6-10, 33 to 400 are named as SCF1, SCF2, SCF3, and SCF4, respectively. The maximum concentration of $\mathrm{Al}_{2} \mathrm{O}_{3}, \mathrm{SCF} 1-3$, and SCF 4 was $60 \mathrm{wt} \%, 25 \mathrm{wt} \%$ and $3 \mathrm{wt} \%$ because of the maximum addition under good filler dispersion and easy sample preparation. The samples with hybrid fillers SCF3/ $\mathrm{Al}_{2} \mathrm{O}_{3}$ were also fabricated and the filler contents were $30 \mathrm{wt} \%, 35 \mathrm{wt} \%$, and $40 \mathrm{wt} \%$. All the concentrations in these composites are in weight percentage (wt\%).

For the preparation of continuous CF-based SMEPC materials shown in Fig. $1 \mathrm{~b}$ and $\mathrm{c}$, the composite prepregs were constructed by impregnating E51 resin with certain ratios of reinforcement T300 fibers and cured under pressure. Next, the fibers were cut into the same size pieces and cross piled layer by layer via hot pressing. We also adopted the vacuum assisted resin infusion molding (VARIM) method to manufacture high-quality and large-scale woven fabric SMEPCs [19]. In the process, dry preform fabrics were placed in an open aluminum pan accompanying several layers laid such as polytetrafluoroethylene (PTFE) release films, PTFE cloth, and flow medium. Then, a plastic vacuum bag was attached to the top of the mold with sealant tape to form a seal, and air was evacuated by a vacuum pump. After connecting the components with epoxy resin and the pump, the mixed and degassed resin from the external baker was then infused into the component until complete impregnation. Finally, the components were kept in vacuum and cured. The filler content of these SMEPCs were 50 vol\%.

\subsection{Scanning electron microscopy (SEM)}

The SMEPC samples were fractured in liquid nitrogen and observed on SEM (Jeol SM-J7500F SEM, Japan and Hitachi S4800, Japan). All the surfaces were sputtered with a thin gold film before observation.

\subsection{Rheological behavior measurement}

To satisfy the demands of low viscosity $(\eta)$ during the casting process, the $\eta$ of samples with maximum filler content for each component at $90{ }^{\circ} \mathrm{C}$ (the first curing stage temperature and the mold preheating temperature) was characterized by a HAAKE MARS II rheometer (Thermo Scientific, Germany) in cone-and-plate configuration (plate diameter $=35 \mathrm{~mm}$, cone angle $=1^{\circ}$ ) under steady shear tests. The shear rate was increased from 0.1 to $100 \mathrm{~s}^{-1}$. The results of rheological properties are shown in Fig. S1 in Supporting Information.

\subsection{Thermogravimetric analysis (TGA)}

The actual filler content and thermal stability were checked by a TGA machine (TA Instruments Q500, USA) under nitrogen atmosphere $\left(60 \mathrm{~mL} \mathrm{~min}^{-1}\right)$ with the temperature range of $25.0-800.0^{\circ} \mathrm{C}$ at a heating rate of $10.0 \mathrm{~K} \mathrm{~min}^{-1}$. Table S1 in Supporting Information has the TGA curve extracted results of filler content of SMEPC samples.

\subsection{Three-point-bending tests}

Three-point-bending tests of the rectangular non-continuous system SMEPC samples with dimensions $80 \times 10 \times 4 \mathrm{~mm}^{3}$ were carried out on a testing machine (Zwick/Roell BT2-FR010TE.A50, Germany) at both $R T$ of ca. $25^{\circ} \mathrm{C}$ and $T_{\mathrm{sw}}$ of ca. $170^{\circ} \mathrm{C}$. The span of the testing machine was $64 \mathrm{~mm}$, and the crosshead speed was $10 \mathrm{~mm} \mathrm{~min}^{-1}$. We also deformed woven CF SMEPC samples with this machine for the bent shapes.

\subsection{Dynamic mechanical thermal analysis (DMTA) and SME analysis}

The DMTA experiments were conducted in a single-cantilever mode using a DMA Q800 (TA instruments, USA), with the temperature ranging from $25.0^{\circ} \mathrm{C}$ to $250.0^{\circ} \mathrm{C}$, heating rate of $3.0 \mathrm{~K} \mathrm{~min}^{-1}$, and frequency of $1 \mathrm{~Hz}$. The quantitative shape memory characteristics like strain fixity ratio $\left(R_{\mathrm{f}}\right)$ and strain recovery ratio $\left(R_{\mathrm{r}}\right)$ were tested and calculated in force-control mode. The size of the samples used with DMTA was $40.0 \times 12.9 \times 2.0 \mathrm{~mm}^{3}$.

\subsection{Simulating computation and experimental test of wind blades' air flow velocity}

The SMEPC wind blades with different components, bending angles, and blade shapes were prepared by designed mold. The compositions of blades were pure SMEP, SMEP/ $\mathrm{Al}_{2} \mathrm{O}_{3}$ composites, and SMEP/SCF3 composites. The diameter and thickness of the blade were $170 \mathrm{~mm}$ and $2 \mathrm{~mm}$, respectively. During the process, one should be emphasized that SME played a role in completely releasing blades from the mold. The simulations about wind speed and pressure on the front and back of the fan blade were implemented through COMSOL Multiphysics . A portable anemometer (smart meter TES-1341, TES Touch Embedded Solutions Inc, Taiwan, China) was used to test the air flow velocity in various positions and bending angles $\left(15^{\circ}, 30^{\circ}\right.$, and $\left.45^{\circ}\right)$ of the blades. The set rotational speed was $600 \mathrm{rpm}$. 

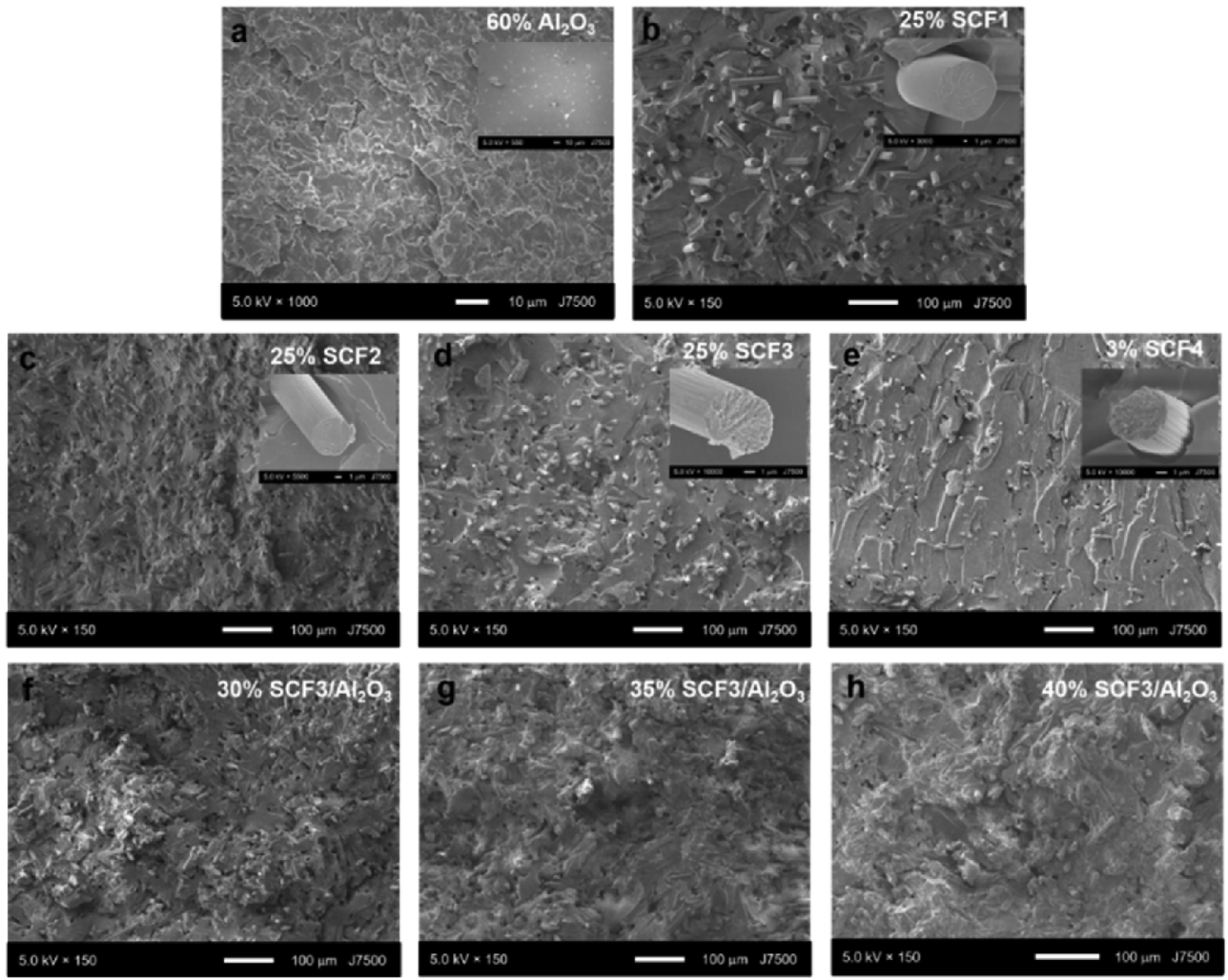

Fig. 2. SEM images of the cryo-fractured surfaces of $60 \mathrm{wt} \% \mathrm{Al}_{2} \mathrm{O}_{3}$ (a); $25 \mathrm{wt} \%$ SCF1 (b); $25 \mathrm{wt} \% \mathrm{SCF} 2$ (c); $25 \mathrm{wt} \%$ SCF 3 (d); 3 wt $\%$ SCF4 (e); $30 \mathrm{wt} \%, 35 \mathrm{wt} \%$ and $40 \mathrm{wt} \%$ of SCF3 $/ \mathrm{Al}_{2} \mathrm{O}_{3}(\mathrm{f}-\mathrm{h})$. The small images inserted in parts a-e are the morphology of single particle and fiber.

\section{Results and discussion}

In this paper, the choice of filler depends on the enhancement modes of the polymer-based composites: nanomaterial-reinforced composites, particle/short fiber-reinforced composites, and continuous fiber-reinforced composites. $\mathrm{Al}_{2} \mathrm{O}_{3}$ and SCF, as non-continuous systems, were fabricated into SMEPCs with different filler contents including 0$60 \mathrm{wt} \% \mathrm{Al}_{2} \mathrm{O}_{3}(0,20,40$, and $60 \mathrm{wt} \%), 0-25 \mathrm{wt} \% \mathrm{SCF} 1-3$ (0, 15, and $25 \mathrm{wt} \%)$, and $0-3 \mathrm{wt} \%$ SCF4 (0, 1, 2, and $3 \mathrm{wt} \%)$. After analyzing the DMTA results of all these samples, as shown in Fig. S2 and Table S1 in Supporting Information, we find that $60 \mathrm{wt} \% \mathrm{Al}_{2} \mathrm{O}_{3}$ and $25 \mathrm{wt} \% \mathrm{SCF} 3$ with the $r_{\mathrm{L} / \mathrm{D}}$ of 33 have the best enhancement effect, which will be discussed in Supporting Information as shown as Fig. S3 [20]. Therefore, the results from non-continues filler system discussed below are all based on these two kinds of fillers and their hybrids, like $60 \mathrm{wt} \% \mathrm{Al}_{2} \mathrm{O}_{3}$, $25 \mathrm{wt} \% \mathrm{SCF} 3$, and $\mathrm{SCF} / \mathrm{Al}_{2} \mathrm{O}_{3}$ (30 wt $\%$, $35 \mathrm{wt} \%$, and $40 \mathrm{wt} \%$ ).

Fig. 2 shows the SEM images of cryo-fractured surfaces of the SMEPCs with the addition of non-continuous system fillers. For all the samples, the $\mathrm{Al}_{2} \mathrm{O}_{3}$ particles, SCFs, and hybrid fillers have uniform distribution in the SMEP matrix. The small images inserted in Fig. 2a-e show the filler size of the single particle and fiber, which is consistent with the size parameter in the materials' specification. The fractured surfaces of the hybrid filler samples are presented in different ways because of the interaction between the particles and the fibers, and the hybrid fillers are more likely to appear agglomerated in the matrix.

Fig. 3 shows typical stress-strain $(\sigma-\varepsilon)$ curves of the non-continuous filler-based SMEPCs at both $R T\left(25^{\circ} \mathrm{C}\right)$ and $T_{\mathrm{sw}}\left(170{ }^{\circ} \mathrm{C}\right)$. The comparable data for $E$, stress at break $\left(\sigma_{\mathrm{b}}\right)$, and strain at break $\left(\varepsilon_{\mathrm{b}}\right)$ are also summarized in Fig. 3b-d and f. Overall, the sample with the fillers of $25 \mathrm{wt} \% \mathrm{SCF} 3$ and $35 \mathrm{wt} \% \mathrm{SCF} 3 / \mathrm{Al}_{2} \mathrm{O}_{3}$ exhibited the best comprehensive mechanical properties, while the presence of more $\mathrm{Al}_{2} \mathrm{O}_{3}$ particles effectively improves the stress along with a decrease in the strain. The comprehensive mechanical properties covering stiffness and deformability are enhanced by SCF3 with the $r_{\mathrm{L} / \mathrm{D}}$ of 33 due to the retardation effect of SCF on cracks. As shown in Fig. 3b, the quasi-static mechanical results from the three-point bending tests are basically consistent with the results from the DMTA. At $R T, 40 \mathrm{wt} \%$ hybrid filler samples have a lower $E$ and the lowest $\sigma_{\mathrm{b}}$ and $\varepsilon_{\mathrm{b}}$, which results from too much hybrid filler dispersing poorly in the epoxy matrix, leading to greater viscosity and more agglomeration defects.

According to Fig. 3e and $\mathrm{f}$, when the temperature increases from $25^{\circ} \mathrm{C}$ to $170^{\circ} \mathrm{C}$, all the SMEPC samples become much more ductile, as evidenced by the lower $E$, lower $\sigma_{\mathrm{b}}$, and higher $\varepsilon_{\mathrm{b}}$. This observation shows that the mechanical performance is strongly dependent on the temperature, and the reinforcement of the fillers shows similar tendencies. Although the strain values at break in Fig. 3a and e do not show great improvement from the numerical results as the calculation method of strain in three-point bending tests, the samples in fact demonstrate good deformation ability around $T_{\mathrm{sw}}$, and they can even fold into a $\mathrm{U}$ or $\mathrm{V}$ shape during testing. Three-point bending tests involve bending, compression, and tension, which is different from the simple tensile or compression test. These have been considered in the testing results.

The SMEPC materials with the addition of longitudinal direction pre-preg CFs, transverse directional pre-preg CFs, and isotropic woven CFs were fabricated and characterized as shown in Fig. 4b in comparison to the non-continuous systems as shown in Fig. 4a. The results of longitudinal directional pre-preg $\mathrm{CF}$ samples achieve maximum $E^{\prime}$ of $37 \mathrm{GPa}$ and $4.4 \mathrm{GPa}$ at $R T$ and above $T_{\mathrm{sw}}$, respectively. In contrast, the stiffness at $R T$ and the recovery force above $T_{\mathrm{sw}}$ of the continuous CFs reinforced SMEPCs are an order of magnitude higher than those in noncontinuous systems. This indicates that below and above $T_{\mathrm{sw}}$ (the whole shape deformation and recovery process), the SMEPC materials keep superior mechanical performance because both of the $E$ ' reach GPa level, which is the basis for structural materials or implementation in related applications. It also indicates that continuous fiber reinforcement is directional, so the woven CF sample exhibits good mechanical performance but not as high as that in longitudinal direction of pre-preg 
a

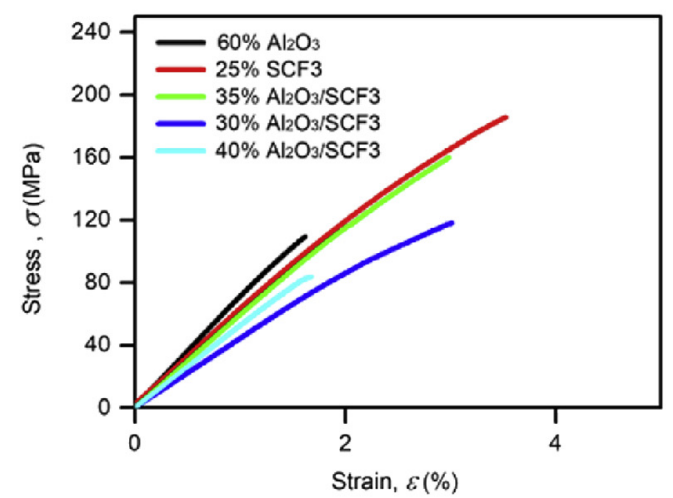

C

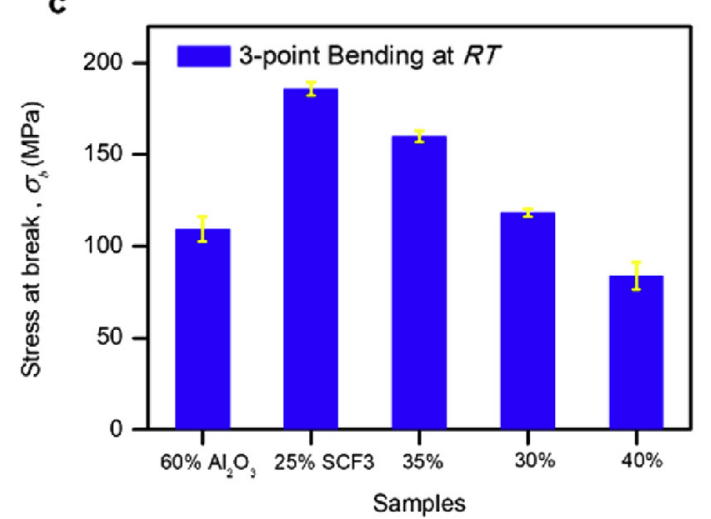

e

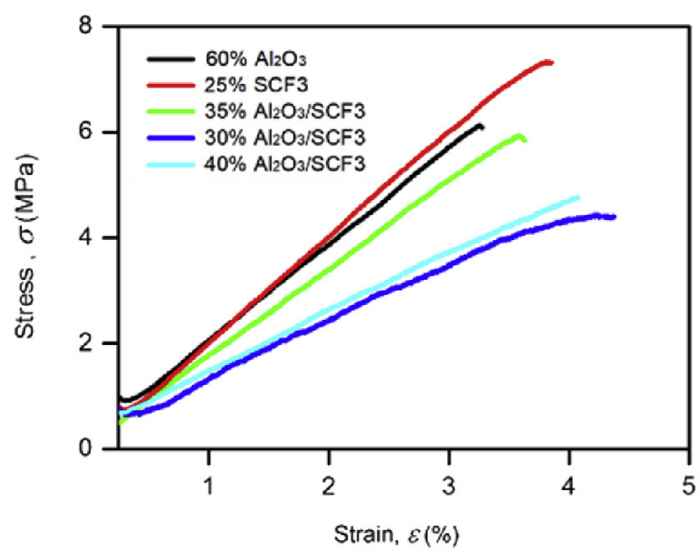

b

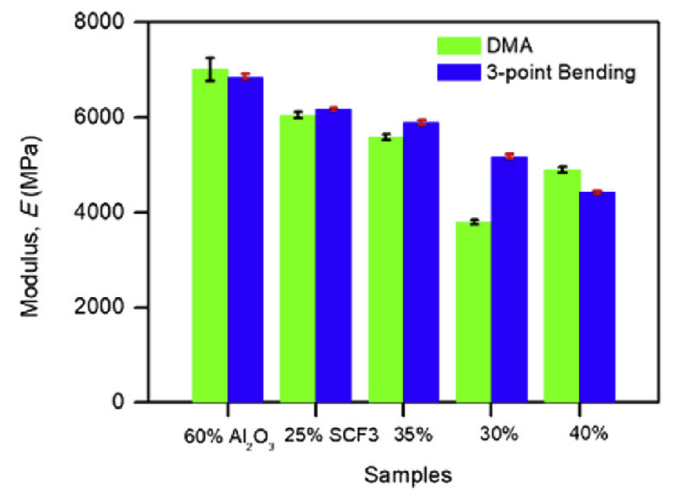

d

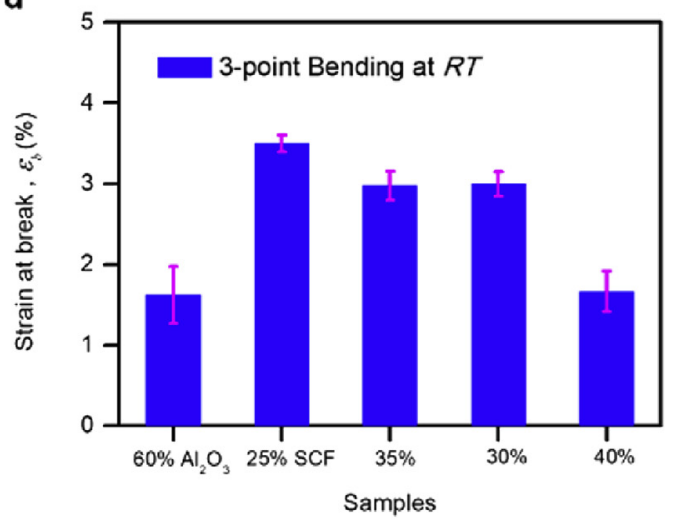

f

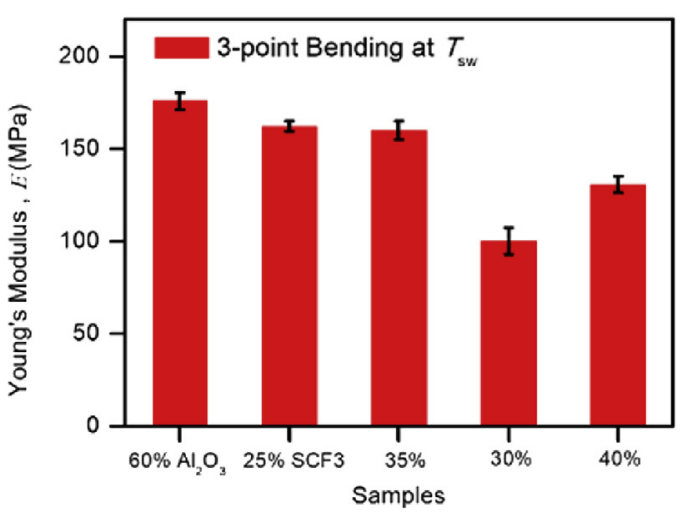

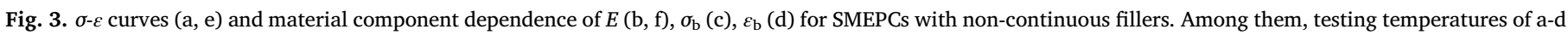
and e-f are $25^{\circ} \mathrm{C}$ and $170{ }^{\circ} \mathrm{C}$, respectively.

samples. The transverse directional reinforced pre-preg $\mathrm{CF}$ samples show no advantage of the long fibers. All the SMEPC samples described have good SME as shown in Fig. S4 in Supporting Information.

In summary, Fig. 5 shows a comparison of the mechanical performance at $R T$ and $T_{\mathrm{sw}}$ among our SMEPCs and some typical shape memory materials (SMMs) reported in literature $[2,3,12,13,15-17,21-31]$. The SMA-based composites demonstrate a high recoverable stress up to $10 \mathrm{GPa}$, but the SME and the $T_{\mathrm{sw}}$ are single, usually confined to $53{ }^{\circ} \mathrm{C}$. In contrast, the typical thermoplastic SMPs like polyethylene (PE), bio-based polyester (BE), polyurethane (PU), and polycyclooctene (PCO) have biocompatibility, and large tensile fracture strain but low fracture stress even below $3 \mathrm{MPa}$. The SME and mechanical properties of general thermoset SMPs using epoxy resin and polyimide (PI) as substrates are in between them. For most of polymer-based SMMs, the mechanical properties are nearly lost during the shape transformation, losing basic strength and stability which are needed for the real applications. For our SCF3 samples, the introduction of $25 \mathrm{wt} \%$ SCF increases the $E^{\prime}$ from ca. 2.3-6.1 GPa and improves the recovery force during shape memory cycles from 33 to over $300 \mathrm{MPa}$. Continuous CF reinforced SMEPCs have further improved $E$ ' to the level of GPa at both $R T$ and $T_{\mathrm{sw}}$ stages, at an order of magnitude to ensure sufficient mechanical strength irrespective of shape memory stage. Such properties approach or exceed most of the SMA composites available in the market.

Enhanced composites are expected to be used in the high-performance scenarios to ensure the required mechanical properties. In addition to the SME, the materials or the structure will be endowed with some extra functions or produce higher efficiency. To show the 

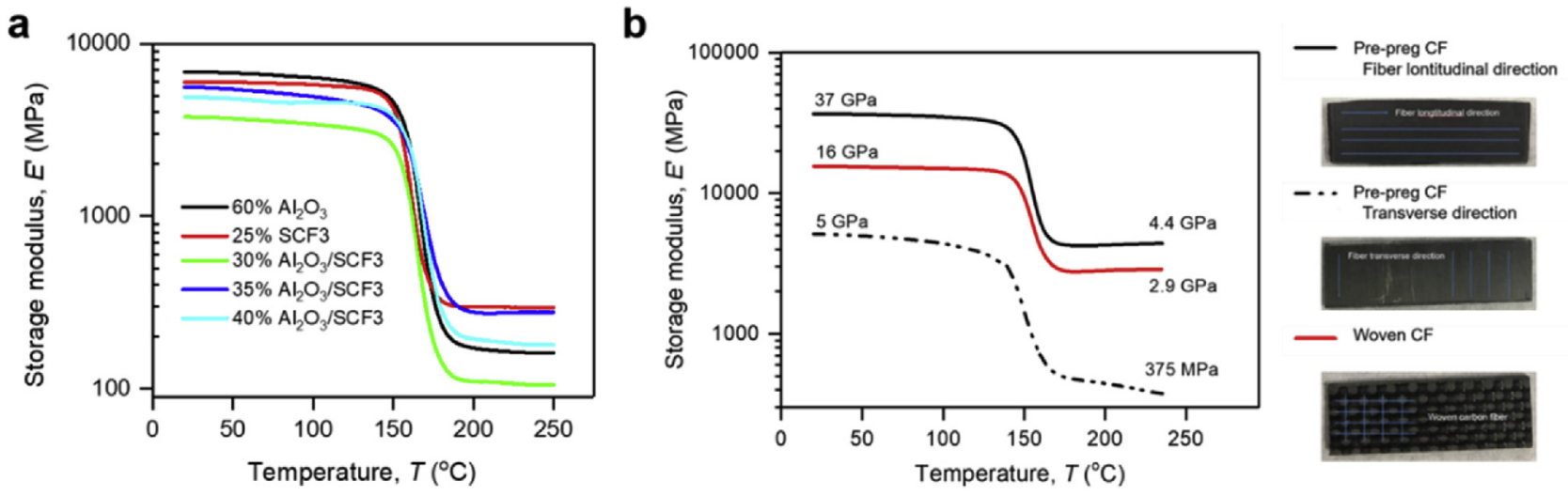

Fig. 4. DMTA curves showing the $E^{\prime}$ change during heating of SMEPCs with non-continuous system fillers (a) and continuous system fillers (b).

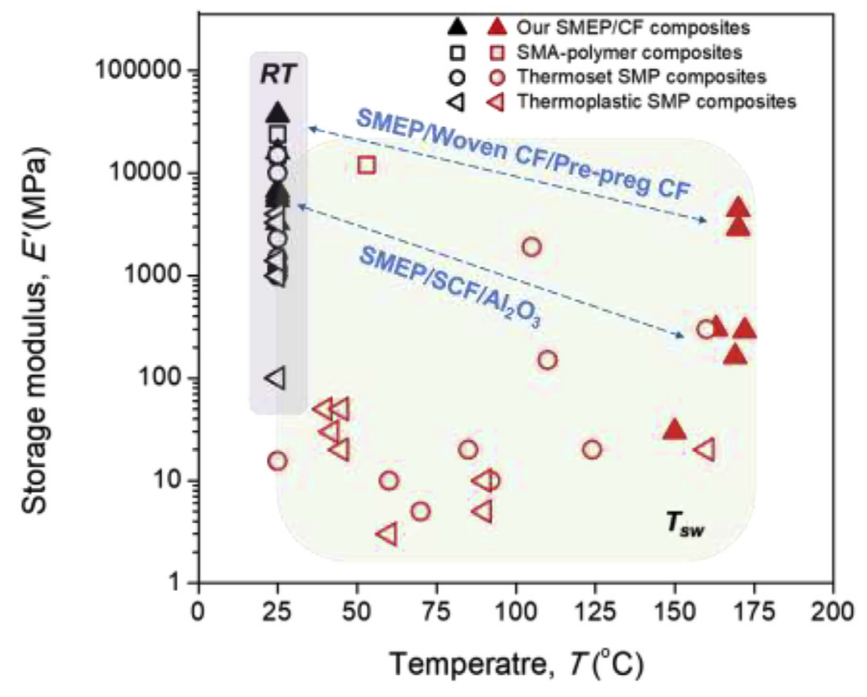

Fig. 5. The comparison of mechanical performance at $R T$ and $T_{\mathrm{sw}}$ among our SMEPCs and some typical high performance SMMs reported in literature. The black symbol stands for the data at $R T$ and the red stands for that at or above $T_{\text {sw. }}$ The solid symbol represents the results of this paper. (For interpretation of the references to colour in this figure legend, the reader is referred to the Web version of this article.)

potential applications of these SMEPCs with superior mechanical and shape memory performances, we designed and prepared a series of typical wind blades with various components and shapes, as shown in Fig. 6. The SMEPC blades were prepared by cast molding and released from the mold through SME. Each flat or bent blade was placed on a fan motor, connected to the power supply, and spun. At the same time, a portable anemometer was used to test air flow velocity from three fixed positions (1, 2, and 3) as marked by the red crosses in Fig. 6 .

Taking $25 \mathrm{wt} \%$ SCF3 blades as an example among the three kinds of blades as shown in Fig. 6, the results of wind velocity over time are shown in Fig. 7 under various bending angles of $15^{\circ}, 30^{\circ}$, and $45^{\circ}$ at three positions of the center, middle, and outer edge. The airflow speed of all three bending angles at position 1 is very low, which is close to zero. Along the outer edge of the test position, the wind speed increases obviously. Among different bending angles of the SMEPC blades, the $30^{\circ}$ bending shows the maximum wind velocity. Compared with the polymer fan blades (the wind speed is usually $9-10 \mathrm{~m} \mathrm{~s}^{-1}$, bending angle is $20-30^{\circ}$ ), high modulus fan blades have little influence on the wind speed, and this high modulus often is necessary in industrial applications. All the bent blades can achieve good shape recovery, that is from bending angle to flat state (angle is $0^{\circ}$ ). The recovery results are shown in Fig. S5 in Supporting Information.

The simulating computation about the wind speed and pressure on the front and back of the fan blades has been investigated through COMSOL Multiphysics as shown in Fig. 8. The pressure on the front and back of the blade is mainly concentrated on the tip and middle of the blades and the connection of positive and negative pressure is located between them. The calculated results on distribution and value of wind velocity are consistent with the experimental data. As the wind speed increases along the outside direction, a wind zone will be generated around the fan blade, and the area of the wind zone will expand with the increase of the bending angle. The deepening in bending angle will cause the concentration of wind speed and hinder the outward transmission of wind.

It indicates from both results of experiment and simulating computation that changes in the shape of these SMEPC blades will result in different wind velocity under the same power supply. Similarly, if the power source is changed into wind motion, the various blade shapes

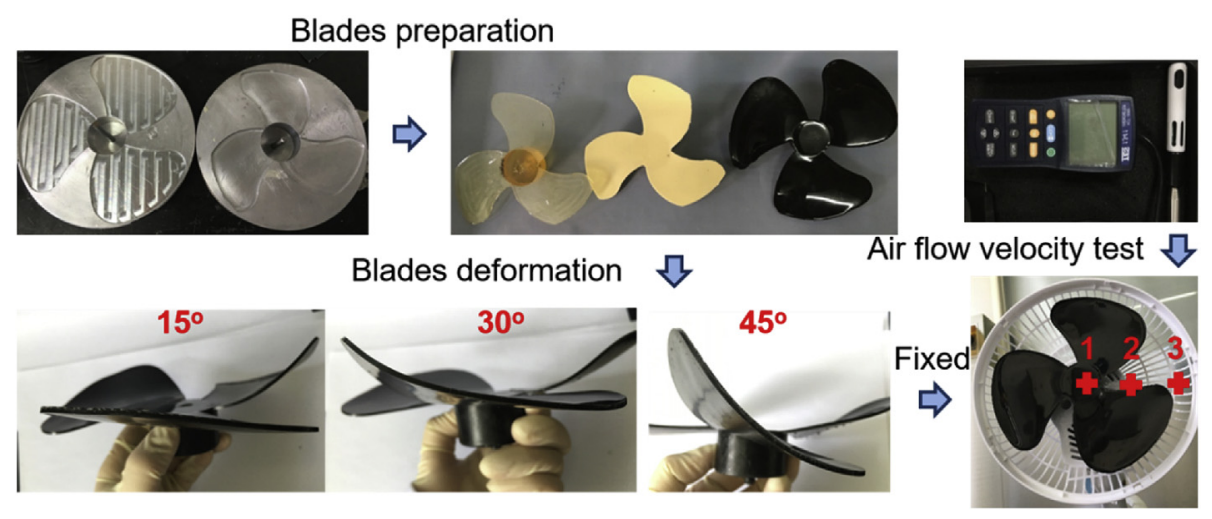

Fig. 6. Photographs showing the process of SMEPCs wind blades' preparation, deformation, and wind velocity tests. 

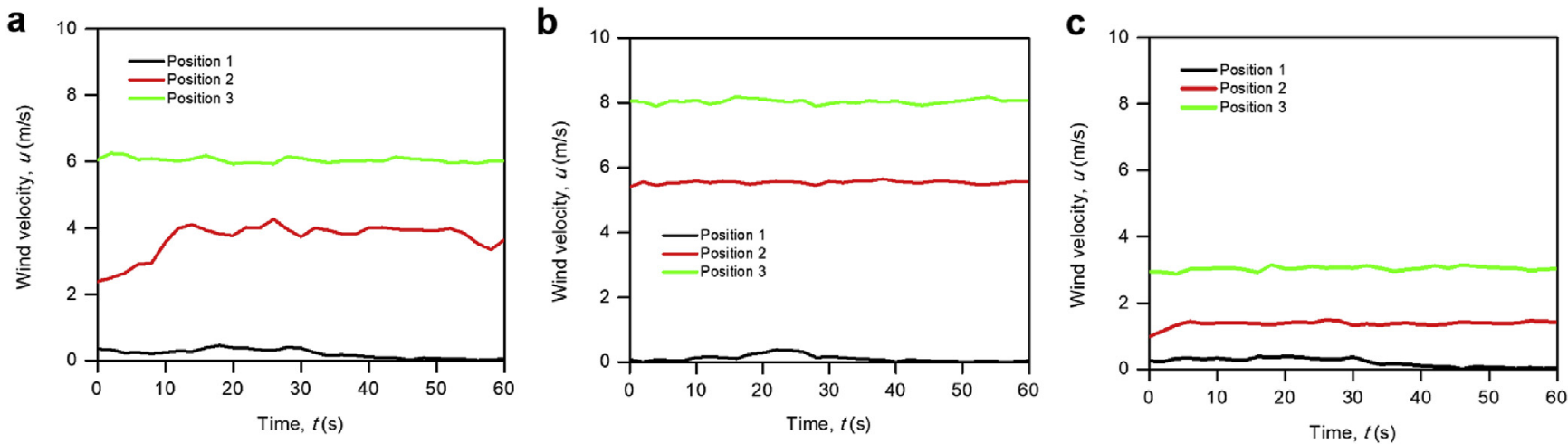

Fig. 7. Wind velocity-time curves showing the airflow speed change with different bending angles of $15^{\circ}$ (a), $30^{\circ}$ (b), and $45^{\circ}$ (c) at three positions.

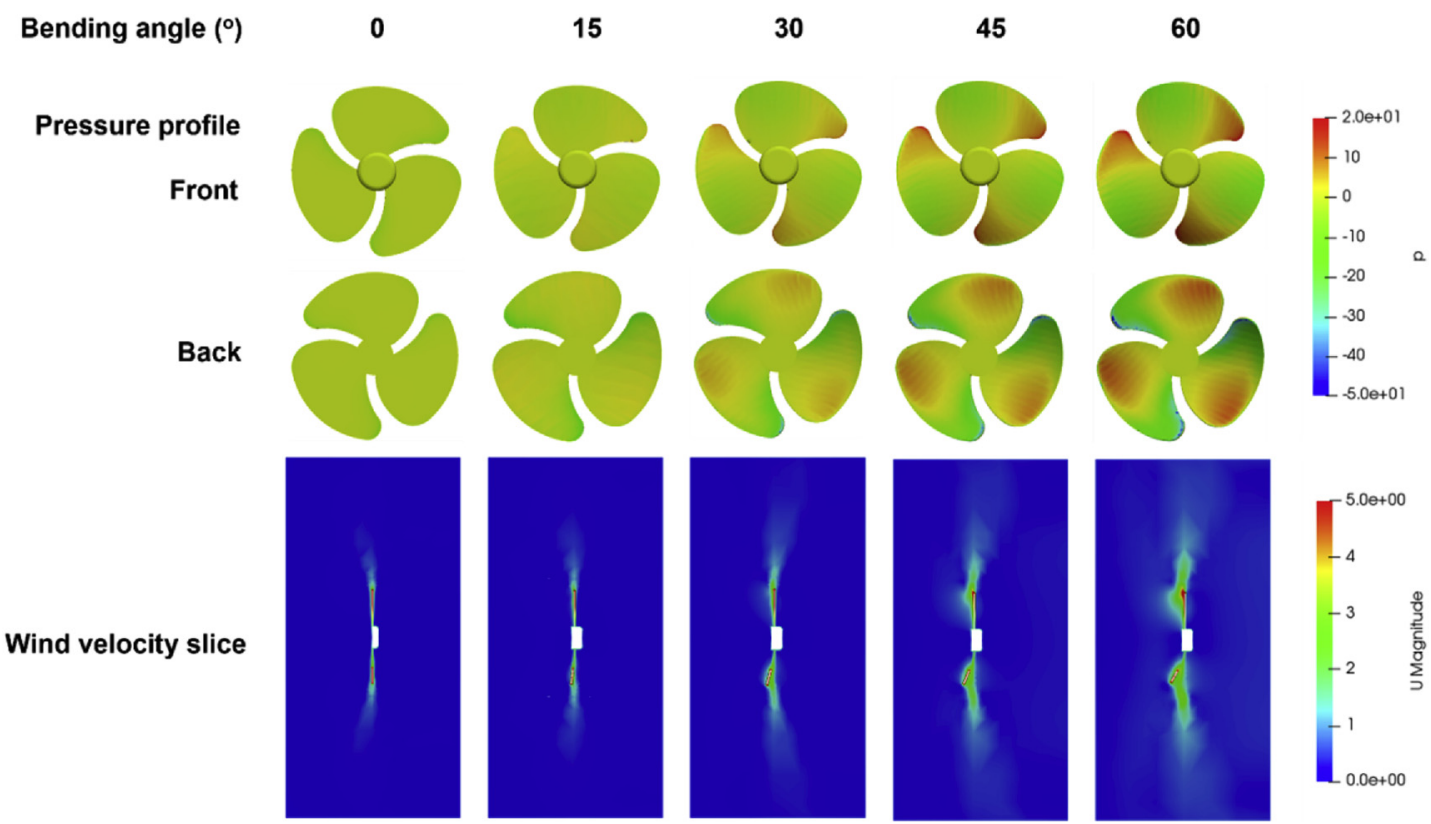

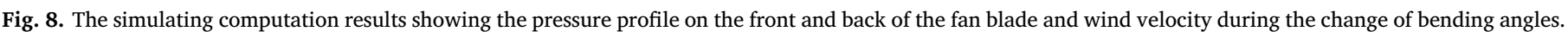

will also bring different kinetic energy conversion and efficiency as the air speed and direction vary.

\section{Conclusions}

A series of CFs reinforced SMEPCs with superior mechanical properties and SMEs were fabricated with various forming methods, and their comprehensive properties and potential applications were systematically investigated. The stiffness at $R T$ and $T_{\mathrm{sw}}$ during shape changing for the continuous CF based SMEPCs can exceed $37 \mathrm{GPa}$ and $4.4 \mathrm{GPa}$, respectively under good shape memory fixation. Furthermore, these SMEPCs demonstrate good recovery and fast response due to the excellent mechanical properties of the fibers and the retardation effect on the crack propagation from the epoxy matrix. In addition, typical wind blades with various components and shapes were designed and prepared demonstrating the potential applications of these SMEPCs. The experimental and numerical simulation results for the air flow velocity with various shapes match well. These CFs reinforced SMEPCs are expected to be used as morphic smart structures in the fields of structural engineering.

\section{Acknowledgements}

This work was financially supported by the National Key Basic
Research Program of China (2016YFA0301200), the National Natural Science Foundation of China (Grant Nos. 11832010 and 11225210, and 11772343), and the Fundamental Research Funds for the Central Universities (CUGB No. 53200859622).

\section{Appendix A. Supplementary data}

Supplementary data to this article can be found online at https:// doi.org/10.1016/j.compscitech.2019.04.014.

\section{References}

[1] W. Wang, D. Liu, Y. Liu, J. Leng, D. Bhattacharyya, Electrical actuation properties of reduced graphene oxide paper/epoxy-based shape memory composites, Compos. Sci. Technol. 106 (2015) 20-24.

[2] M. Yoonessi, Y. Shi, A.S. Daniel, L.C. Marisabel, M.T. Dean, R.A. Weiss, A.M. Michael, Graphene polyimide nanocomposites, thermal, mechanical, and high-temperature shape memory effects, ACS Nano 6 (2012) 7644-7655.

[3] Y.Y. Liu, J. Zhao, L.Y. Zhao, W. Li, H. Zhang, X. Yu, Z. Zhang, High performance shape memory epoxy/carbon nanotube nanocomposites, ACS Appl. Mater. Interfaces 8 (2016) 311-320.

[4] Z. Wang, J. Zhao, M. Chen, M. Yang, L. Tang, Z.M. Dang, F. Chen, M. Huang, $\mathrm{X}$. Dong, Dually actuated triple shape memory polymers of cross-linked polycyclooctene-carbon nanotube/polyethylene nanocomposites, ACS Appl. Mater. Interfaces 6 (2014) 20051-20059.

[5] L. Fang, S. Chen, T. Fang, J. Fang, C. Lu, Z. Xu, Shape-memory polymer composites selectively triggered by nearinfrared light of two certain wavelengths and their applications at macro-/microscale, Compos. Sci. Technol. 128 (2017) 106-116. 
[6] W. Voit, T. Ware, R.R. Dasari, P. Smith, L. Danz, D. Simon, S. Barlow, S.R. Marder, K. Gall, High-strain shape-memory polymers, Adv. Funct. Mater. 20 (2010) $162-171$.

[7] L.Y. Zhao, J. Zhao, Y.Y. Liu, Y.F. Guo, L.P. Zhang, Z. Chen, H. Zhang, Z. Zhang, Continuously tunable wettability by using surface patterned shape memory polymers with giant deformability, Small 12 (2016) 3327-3333.

[8] H. Xie, J. Shao, Y. Ma, J. Wang, H. Huang, N. Yang, H. Wang, C. Ruan, Y. Luo, Q. Wang, P. Chu, X. Yu, Biodegradable near-infrared-photoresponsive shape memory implants based on black phosphorus nanofillers, Compos. Sci. Technol. 163 (2018) 11-21.

[9] J. Zhao, M. Chen, X. Wang, X. Zhao, Z. Wang, Z.M. Dang, L. Ma, G.H. Hu, F. Chen, Triple shape memory effects of cross-linked polyethylene/polypropylene blends with cocontinuous architecture, ACS Appl. Mater. Interfaces 5 (2013) 5550-5556.

[10] Y. Meng, J. Jiang, M. Anthamatten, Body temperature triggered shape-memory polymers with high elastic energy storage capacity, J. Polym. Sci., Part B: Polym. Phys. 54 (2016) 1397-1404.

[11] H. Xie, L. Li, X. Deng, C. Cheng, K. Yang, Y. Wang, Reinforcement of shape-memory poly(ethylene-co-vinyl acetate) by carbon fibre to access robust recovery capability under resistant condition, Compos. Sci. Technol. 157 (2018) 202-208.

[12] X. Wang, J. Zhao, M. Chen, L. Ma, X. Zhao, Z.M. Dang, Z. Wang, Improved selfhealing of polyethylene/carbon black nanocomposites by their shape memory effect, J. Phys. Chem. B 117 (2013) 1467-1474.

[13] X. Feng, L. Zhao, X. Mi, Y. Li, H. Xie, X. Yin, B. Gao, Improved shape memory composites combined with TiNi wire and shape memory epoxy, Mater. Des. 50 (2013) 724-727.

[14] M. Tehrani, A.Y. Boroujeni, T.B. Hartman, T.P. Haugh, S.W. Case, M.S. Al-Haik, Mechanical characterization and impact damage assessment of a woven carbon fiber reinforced carbon nanotube-epoxy composite, Compos. Sci. Technol. 75 (2013) 42-48.

[15] J. Guo, Z. Wang, L. Tong, H. Lv, W. Liang, Shape memory and thermo-mechanical properties of shape memory polymer/carbon fiber composites, Compos. Part AAppl. S76 (2015) 162-171.

[16] Z. Wang, J. Liu, J. Guo, X. Sun, L. Xu, The study of thermal, mechanical and shape memory properties of chopped carbon fiber-reinforced TPI shape memory polymer composites, Polymers 9 (2017) 594.

[17] R.R. Zhang, X.G. Guo, Y.J. Liu, J.S. Leng, Theoretical analysis and experiments of a space deployable truss structure, Compos. Struct. 112 (2014) 226-230.

[18] X. Lan, Y. Liu, H. Lv, X. Wang, J. Leng, S. Du, Fiber reinforced shape-memory polymer composite and its application in a deployable hinge, Smart Mater. Struct. 18 (2009) 024002.
[19] K. Zhang, Y. Gu, M. li, Z. Zhang, Effect of rapid curing process on the properties of carbon fiber/epoxy composite fabricated using vacuum assisted resin infusion molding, Mater. Des. 54 (2014) 624-631.

[20] P.J. Hine, H.R. Lusti, A.A. Gusev, Numerical simulation of the effects of volume fraction, aspect ratio and fibre length distribution on the elastic and thermoelastic properties of short fibre composites, Compos. Sci. Technol. 62 (2002) 1445-1453.

[21] K. Wei, G. Zhu, Y. Tang, G. Tian, J. Xie, Thermomechanical properties of shapememory hydro-epoxy resin, Smart Mater. Struct. 21 (2012) 055022.

[22] Z. Wang, L. Xu, X. Sun, M. Shi, J. Liu, Fatigue behavior of glass-fiber-reinforced epoxy composites embedded with shape memory alloy wires, Compos. Struct. 178 (2017) 311-319.

[23] W. Wang, D. Liu, Y. Liu, J. Leng, D. Bhattacharyya, Electrical actuation properties of reduced graphene oxide paper/epoxy-based shape memory composites, Compos. Sci. Technol. 106 (2015) 20-24.

[24] P. Taynton, H. Ni, C. Zhu, K. Yu, S. Loob, Y. Jin, H.J. Qi, W. Zhang, Repairable woven carbon fiber composites with full recyclability enabled by malleable polyimine networks, Adv. Mater. 28 (2016) 2904-2909.

[25] Z. Tang, D. Sun, D. Yang, B. Guo, L. Zhang, D. Jia, Vapor grown carbon nanofiber reinforced bio-based polyester for electroactive shape memory performance, Compos. Sci. Technol. 75 (2013) 15-21.

[26] M. Raja, S.H. Ryu, A.M. Shanmugharaj, Thermal, mechanical and electroactive shape memory properties of polyurethane (PU)/poly (lactic acid) (PLA)/CNT nanocomposites, Eur. Polym. J. 49 (2013) 3492-3500.

[27] W. Qin, F. Vautard, L.T. Drzal, J. Yu, Mechanical and electrical properties of carbon fiber composites with incorporation of graphene nanoplatelets at the fiber-matrix interphase, Compos. B Eng. 69 (2015) 335-341.

[28] M. Dawood, M.W. El-Tahan, B. Zheng, Bond behavior of superelastic shape memory alloys to carbon fiber reinforced polymer composites, Compos. B Eng. 77 (2015) 238-247.

[29] D.I. Chukov, A.A. Stepashkin, A.V. Maksimkin, V.V. Tcherdyntsev, S.D. Kaloshkin, K.V. Kuskov, V.I. Bugakov, Investigation of structure, mechanical and tribological properties of short carbon fiber reinforced UHMWPE-matrix composites, Compos. B Eng. 76 (2015) 79-88.

[30] Y.C. Jung, H.J. Yoo, Y.A. Kim, J.W. Cho, M. Endo, Electroactive shape memory performance of polyurethane composite having homogeneously dispersed and covalently crosslinked carbon nanotubes, Carbon 48 (2010) 1598-1603.

[31] A.B. Leonardi, L.A. Fasce, I.A. Zucchi, C.E. Hoppe, E.R. Soulé, C.J. Pérez, R.J.J. Williams, Shape memory epoxies based on networks with chemical and physical crosslinks, Eur. Polym. J. 47 (2011) 362-369. 